\title{
REVISIÓN
}

\section{Fatty acid hydroperoxides pathways in plants. A review}

\author{
By M.- L. Fauconnier* and M. Marlier \\ U.E.R. Chimie Générale et Organique, Faculté Universitaire des Sciences Agronomiques. \\ 2, Passage des Déportés -B-5030 Gembloux- Belgique. Fauconnier@fsagx.ac.be
}

\section{RESUMEN}

Las rutas de los hidroperóxidos de ácidos grasos en plantas. Una revisión.

El presente artículo se centra en las rutas de los hidroperóxidos de ácidos grasos, principalmente la hidroperóxido liasa y la hidroperóxido dehidrasa. Se presenta para cada enzima, la definición, distribución y localización subcelular.

Se da atención particular a los mecanismos de reacción y a la especificidad de sustrato.

También se discuten los papeles fisiológicos de los productos de reacción.

PALABRAS-CLAVE: Hidroperóxido dehidrasa (ruta) Hidroperóxido liasa (ruta) - Planta - Revisión (artículo).

\section{SUMMARY}

Fatty acid hydroperoxides pathways in plants. A review.

The present paper focusses on the fatty acid hydroperoxides pathways, mainly hydroperoxide lyase and hydroperoxide dehydrase. For each enzyme, the definition, occurrence and subcellular localization is presented. Particular attention is given to reaction mecanisms and to substrate specificity. Physiological roles of reaction products are also discussed.

KEY-WORDS: Hydroperoxide dehydrase (pathway) Hydroperoxide lyase (pathway) - Plant - Review (paper).

\section{INTRODUCTION}

Fatty acid hydroperoxides are key components formed by the action of lipoxygenase (E.C. 1.13.11.12) on $1-Z, 4-Z$ pentadiene containing fatty acids (mainly linoleic and linolenic acids in plants). Depending on the origin of the lipoxygenase and on the reaction conditions, variable amounts of 13 and/or 9 hydroperoxides are formed. The hydroperoxides can be further degraded in a variety of products involved in essential physiological roles in plants (jasmonic acid, traumatine) or responsible of the caracteristic green notes of plants and fruits (C-6 or C-9 aldehydes and alcohols). Two main pathways are described: the hydroperoxide lyase one leads to aldehydes and oxo- acids synthesis and the dehydrase one which furnishes $a, \gamma$-cetols and a cyclic compound. Other enzymatic conversions of fatty acid hydroperoxides exist in some plants (divinyl ethers synthesis, hydroperoxide isomerase and hydroperoxide dependant peroxygenase and epoxygenase), they are also presented here.

\section{HYDROPEROXIDE LYASE PATHWAY}

\subsection{Definition}

Hydroperoxide lyase catalyzes the cleavage of linoleic and linolenic acid hydroperoxides into aldehydes and $\omega$-oxo-acids. The break takes place between the carbon which contains the hydroperoxide group and the proximate ethylenic carbon. The figure 1 represents the action of hydroperoxide lyase on 9 and 13 hydroperoxide of linolenic and linoleic acids (Martini and lacazio, 1995).
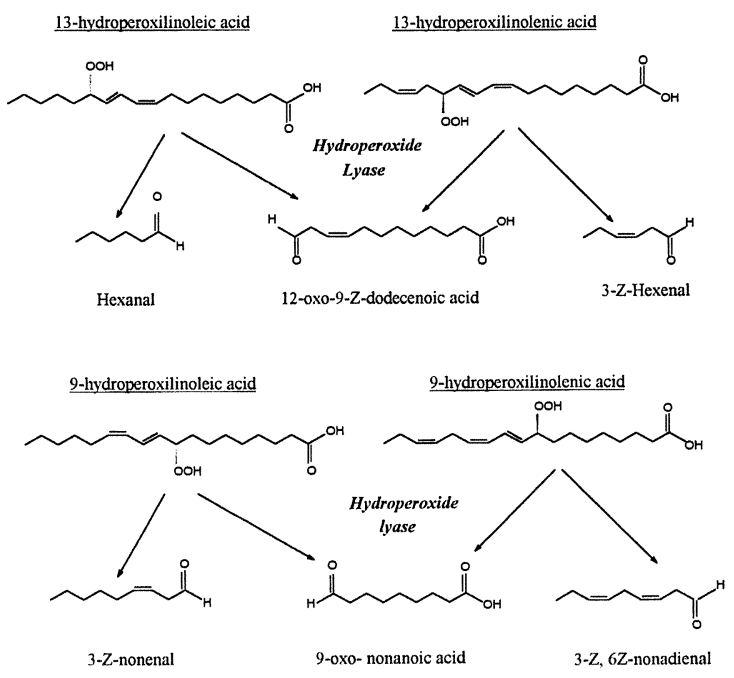

Figure 1

Hydroperoxide degradation by hydroperoxide lyase (Martini and lacazio, 1995). 


\subsection{Occurence}

Hydroperoxide lyase was first suspected in banana by Tressl and Drawert (1973) but these authors were unable to isolate the enzyme system responsible for the production of aldehydes. This last system was demonstrated later in watermelon seedlings (Vick and Zimmerman, 1976) and in cucumber fruits (Galliard and Phillips, 1976). The enzyme was also identified in alfalfa seedlings (Sekiya et al., 1979), soybean seeds (Matoba et al., 1985), tomato fruits (Galliard et al., 1977), pear fruits (Kim and Grosch, 1981), apple fruits (Schreier and Lorenz, 1982), cultured tobacco cells (Sekyia et al., 1984), kidney bean leaves (Matthew and Galliard, 1978), spinach leaves chloroplasts (Vick and Zimmerman, 1987), tea leaves chloroplasts (Hatanaka et al., 1982) and green bell pepper fruits (Shibata et al., 1995a). If we add to this list the study of Sekyia et al. (1983) which reveals variable amounts of hydroperoxide lyase activity in 28 different plant leaves, we can conclude that the enzyme is widespread in the plant kingdom.

The enzyme is found in green and non-green tissues and is located in different organs such as leaves, roots, cotyledons, seeds and fruits.

\subsection{Subcellular localisation}

Hydroperoxide lyase is a membrane-bound enzyme requiring detergent solubilization, usually Triton X-100 (Gardner, 1991). In green tissues, chloroplast thylakoid membranes appear to be the major site of location (Hatanaka et al., 1982; GotzSchmidt et al., 1986; Vick et Zimmerman, 1987, Gardner, 1991). In non-green tissue, other sites of location are described. Indeed, in cucumber fruits, Wardale et al. (1978) determine that the enzyme was present in plasma and golgi membranes and in endoplasmic reticulum. In the peel of the fruit, the lyase was located in chloroplasts. In green bell pepper fruits (Shibata et al., 1995a) the activity is found in outer parenchymal cells of the pericarp where most of the chloroplasts of the fruit are located.

\subsection{Properties}

The optimum $\mathrm{pH}$ ranges from 5.5 for green bell pepper fruits (Shibata et al., 1995a) and tomato fruits (Schreier and Lorenz, 1982) to 8 for cucumber cotyledons (Matsui et al., 1989). Hydroperoxide lyase from pear fruits (Kim et Grosch, 1981), tea leaves (Matsui, 1991) and soybean cotyledons (Olias et al., 1990) works at neutral $\mathrm{pH}$. The pl of the enzyme in one isoform of green bell pepper fruits is 8.3 (Shibata et al., 1995a). The molecular weight is high: $170.000 \mathrm{Da}$ for green bell pepper fruits (Shibata et al., 1995a), 220.000 Da in spinach leaves (Vick and Zimmerman, 1987 ), between 240.000 and $260.000 \mathrm{Da}$ in soybean cotyledons (Olias et al., 1990) and higher than 200.000
Da in tomato fruits (Schreier and Lorenz, 1982). The enzyme is thought to be a trimer of 55.000 Da subunits in green bell pepper fruits while it is a tetramer composed of four subunits of $62.000 \mathrm{Da}$ in soybean cotyledons. Recently, Shibata et al. (1995b) have demonstrated that hydroperoxide lyase was a heme protein.

\subsection{Substrate specificity}

Hydroperoxide lyases can be classified into two categories based on their substrate specificity: the 9hydroperoxide specific enzyme which cleaves exclusively the 9-isomer and the 13-specific one which uses the 13-isomer as substrate. Pear fruits hydroperoxide lyase belongs to the first type (Kim and Grosch, 1981) while watermelon seedlings (Vick and Zimmerman, 1976), tea leaves (Hatanaka et al., 1982), cultured tobacco cells (Sekyia et al., 1984), tomato fruits (Schreier and Lorenz, 1982), alfalfa seedlings (Sekyia et al., 1979) and green bell pepper fruits (Shibata et al., 1995a) lyases are of the second type. In kidney beans (Matthew and Galliard, 1978), cucumber seedlings (Sekyia et al., 1979) and fruits (Galliard and Phillips, 1976), and in soybean seedlings (Gardner et al., 1991) the enzyme is described as cleaving both substrates. This last feature can be explained by the fact that the enzyme belongs to a third type of hydroperoxide lyase which would accept both substrates or by the fact that different isoenzymes are present in the plant. Indeed, Matsui et al. (1989) demonstrated that an enzyme extracted from cucumber cotyledons consisted of two isomers, one cleaving the 9-isomer and the other one the 13-isomer.

The enzyme in non-photosynthetic plant tissues is typically more active with linoleic acid hydroperoxides whereas hydroperoxide lyase in photosynthetic organs usually shows high activity with linolenic acid hydroperoxide (Sekyia et al., 1984).

A systematic study of substrate-specificity of hydroperoxide lyase extracted from tea leaves was undertaken using synthetic substrates (Hatanaka et al., 1992; Hatanaka, 1993). When 13-hydroperoxy (9Z, $11 \mathrm{E}, 15 \mathrm{Z}$ ) octadecatrienoic acid is replaced by 13hydroperoxy $(6 Z, 9 Z, 11 E)$ octadecatrienoic acid, the reactivity is reduced to $22 \%$ of the original one. 15 hydroperoxy $(5 Z, 8 Z, 11 Z, 13 E)$ eicosatetraenoic acid is not a substrate for the enzyme while lipoxygenase is able to synthetize it. When the carboxyl group is converted to a methyl ester or an alcohol, the reactivity is reduced to 27 and $53 \%$ respectivelly. Moreover, the $S$ configuration is favoured by the tea enzyme. This last result has also be obtained by Matoba et al. (1985) with soybean seeds where 13-S-hydroperoxide of linoleic acid is preferred. Gardner et al. (1991) report that the 9-S-hydroperoxide is used by soybean seeds and cotyledons. Further studies were undertaken by Hatanaka's team using synthetized substrates. Figure 2 presents the hydroperoxides used for this study. For both dienoic and trienoic hydroperoxides, $n$ was 
increased gradually for a total number of carbon ranging from 14 to 24 .<smiles>CCCCCC(C=CC=CCCCCC(=O)O)OO</smiles>

Dienoic hydroperoxides<smiles>CC/C=C/CC(/C=C/C=C/CC(=O)O)OO</smiles>

Trienoic hydroperoxides

Figure 2

Fatty acids hydroperoxides used by Hatanaka (1993) to study the specificity of tea leaf hydroperoxide lyase.

In all cases, the authors observed that the reactivity was ten times higher with the trienoic hydroperoxides compared to the dienoic ones. The activity increased gradually with the carbon number until the C-22 containing substrate and decreased there after. The substrate requirements for tea leaves hydroperoxide lyase is thus a C-18 straight chain fatty acid with a free carboxyl group, attachment of the hydroperoxide group to $\omega-6$ with a $S$ configuration, an $E$ double bond at $\omega-7$ and a $Z$ double bond at $\omega-9$. When a double bound is introduced between the $C(\omega-3$ and the $C \omega-4$ it is very effective in increasing the activity whereas the introduction of a double bound between the $C(\omega-10$ and the terminal $\mathrm{COOH}$ (case of $\gamma$-linolenic acid), the activity decreases strikingly. The recognition of the chain length ranging from the $\omega-10$ carbon to the terminal carbonyl is not so strict.

\subsection{Enzyme inhibition}

The study of tea leaves hydroperoxide lyase substrate-inhibition (Matsui et al., 1991 and 1992) reveals that the enzyme is irreversibly inhibited by 13hydroperoxide of linoleic acid. Degradation of 9hydroperoxide of linoleic acid is little catalyzed by the enzyme, but this substrate also inactivates it whereas other organic hydroperoxides and $\mathrm{H}_{2} \mathrm{O}_{2}$ do not act as inactivator. The enzyme is protected from substrate inhibition by dithiothreitol and is inhibited by $\mathrm{Hg}_{2} \mathrm{Cl}_{2}$ suggesting the implication of an essential $\mathrm{SH}$ group near the reaction center of the enzyme. Organic antioxidant such as a-tocopherol, nordihydroguaiaretic acid, butylated hydroxyanisole and butylated hydroxytoluene also protect the enzyme against inactivation, meaning that radical species are implicated in the catalysis. Hydroperoxide lyase from green bell pepper fruits is inhibited by salicylic acid and salicylhydroxamic acid, acting as metal chelating agents (Shibata et al., 1995a). This last result was confirmed by the discovery of a heme group in the enzyme (Shibata et al., 1995b).

\subsection{Catalysis mecanism}

Two different mecanisms are described in hydroperoxide lyase catalysis. The heterolytic one is typical for higher plants and leads to the synthesis of aldehydes and oxoacids as presented in figure 1. In algae (Vick and Zimmerman, 1989; Adrianarison et al., 1989) and mushrooms (Wurzenberger and Grosch, $1984 a$ et b), a homolytic mecanism takes place, furnishing an alcohol or a hydrocarbon and an oxoacid. The alga Chlorella pyrenoidosa converts the 13hydroperoxide of linoleic or linolenic acids respectively to pentane or pentene and 13-oxo-9Z, 11E-tridecanoic acid (Vick and Zimmerman, 1989). The blue green alga Oscillatoria exhibits the same activity but furnishes pentanol rather than pentane (Andrianarison et al., 1989). In mushrooms, lipoxygenase probably synthetizes a special hydroperoxide, the 10-isomer rather than a 13-or a 9-isomer. The lyase cleaves the hydroperoxide into 1-octen-3-ol from the 10-Shydroperoxide of linoleic acid, or 1,5 octadien-3-ol from the 10-S-hydroperoxide of linolenic acid, and 10-0xo-8E decenoic acid (Wurzenberger and Grosch, 1984a and b) (figure 3). The grass Agropyron repens forms volatile products characteristic of both homolytic and heterolytic mecanisms (Berger et al., 1986).
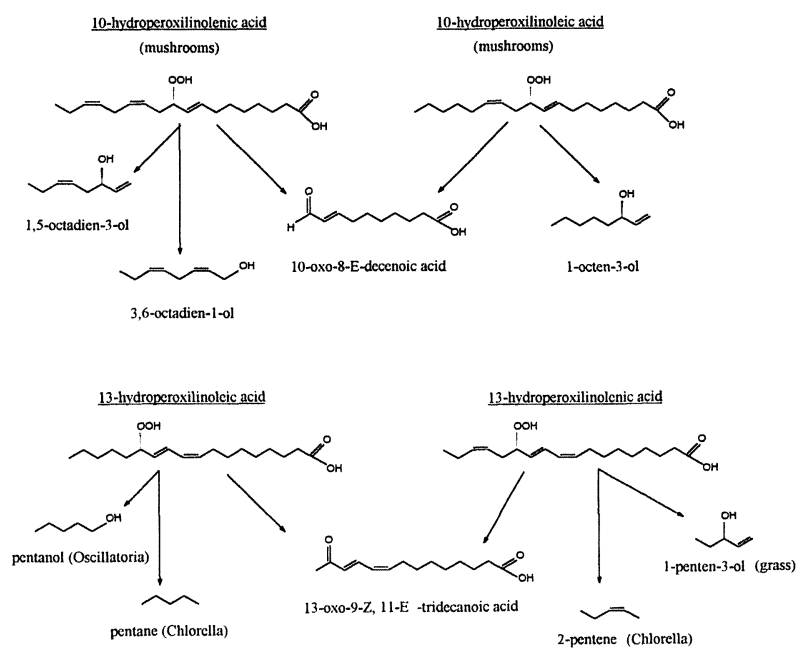

Figure 3

Homolytic cleavage of fatty acid hydroperoxides in mushrooms, algae and grass (Gardner, 1991). 
Hatanaka et al. (1986) have studied the heterolytic cleavage mecanism using labelled hydroperoxides. As shown in figure 4 , one of the labelled oxygen from the hydroperoxide group is transferred to the oxoacid and not to the aldehyde. This mecanism is similar to that described by Gardner an Plattner (1984) for the cleavage of hydroperoxide from linoleic acid into aldehyde and oxoacid by a strong Lewis aprotic solvent.

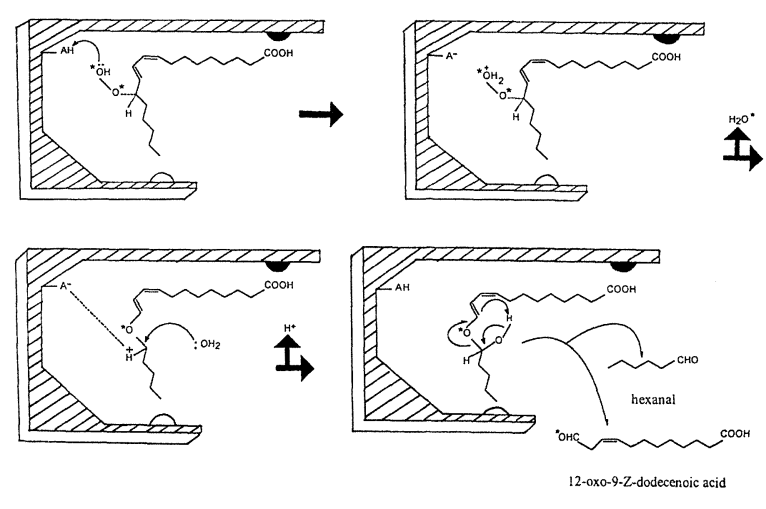

Figure 4

Cleavage of 13-hydroperoxide of linoleic acid by hydroperoxide lyase of tea chloroplasts according to Hatanaka et al. (1986).

\subsection{Physiological roles of hydroperoxide lyase products}

The exact function of hydroperoxide lyase is still unclear altough most hypothesis focus on a role in plant defense and wound repair. One of the hydroperoxide lyase products originating from linoleic acid, 2-E-hexenal, is an effective fungicide (Zeringue And Mc Cormick, 1989). It is also demonstrated that the molecule has a bactericide (Schildknecht and Rauch, 1961) and an insecticide effect (Lyr and Banasiak, 1983). The other cleavage product, 12-oxo-10-E-dodecenoic acid, is easily oxidized non-enzymatically to E-2-dodecendioic acid commonly called traumatic acid. This acid is wound plant hormone causing cell division near the wound site resulting in the formation of a protective callus (Zimmerman and Coudron, 1979).

\section{HYDROPEROXIDE DEHYDRASE}

\subsection{Definition}

Hydroperoxide dehydrase (E.C. 4.2.1.92) is the revised nomenclature for an enzyme that was previously tought to be two separate enzymes, namely hydroperoxide isomerase and hydroperoxide cyclase. The hydroperoxide isomerase and cyclase activities were discovered by Zimmerman (1966) and by
Zimmerman and Feng (1978), respectively. Hydroperoxide isomerase was supposed to directly catalyze the transformation of hydroperoxide from linolenic and linoleic acids into $a$ and $\gamma$-ketols, while hydroperoxide cyclase supposedly transformed 13-Shydroperoxide of linolenic acid into 12-oxo-phytodienoic acid. Recent works undertaken by four different teams suggested that allene oxyde was the common intermediate to the formation of ketols and 12-oxophytodienoic acid (Hamberg, 1987; Crombie and Morgan, 1987; Corey et al., 1987; Brash et al., 1987). This intermediate is highly unstable, having a half life of $33 \mathrm{~s}$ at $0^{\circ} \mathrm{C}$. After the allene oxide is formed from the 9$S$ or 13-S-hydroperoxide of linoleic acid, spontaneous non-enzymatic hydrolysis affords $\alpha$ and $\gamma$-ketols. The allene oxide formed from 13-S-hydroperoxide of linolenic acid spontaneously converts into ketols but also into 12-oxo-phytodienoic acid (enzymatically or not) at a level of about $10 \%$ of total products (see figure 5).

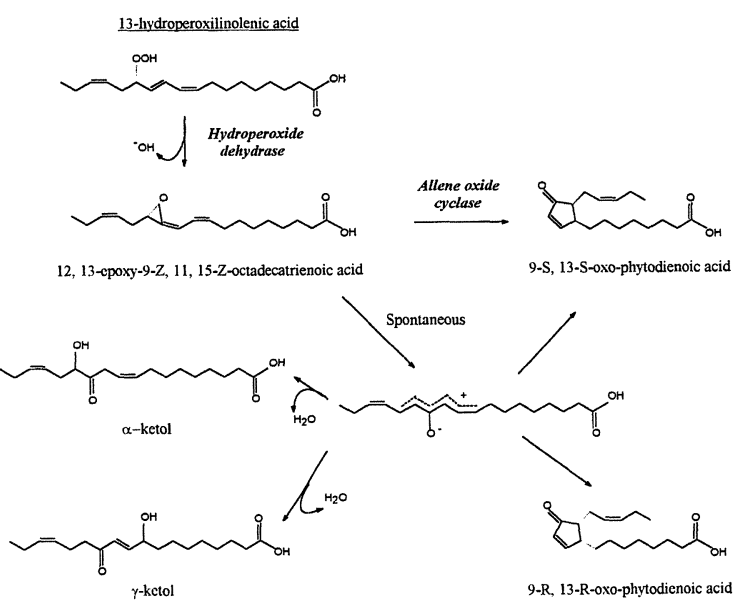

Figure 5

Action of hydroperoxide dehydrase on 13-hydroperoxide of linolenic acid (Martini and lacazio, 1995).

\subsection{Occurence}

The enzyme was first described in flax seed (as hydroperoxide isomerase) by Zimmerman (1966) and Zimmerman and Vick (1970). It was later identified in corn (Gardner, 1970), barley (Yabuuchi and Amaha, 1976), lettuce, oat, spinach, sunflower, wheat (Vick and Zimmerman, 1979) and cotton seedlings (Vick and Zimmerman, 1981), eggplant (Groosman et al., 1983), broad bean (Vick and Zimmerman, 1983) and spinach leaves (Vick and Zimmerman, 1987). Two species of coral (Corey et al., 1987; Brash et al., 1987) and an alga (Vick and Zimmerman, 1989) also exhibit hydroperoxide dehydrase activity. The enzyme occurs thus not only in most cereal seeds and seedling but also in fruits and leaves. 


\subsection{Subcellular localisation}

Like hydroperoxide lyase, hydroperoxide dehydrase is a membrane bound enzyme and requires thus detergent for solubilization (Vick and Zimmerman, 1981; Vick and Zimmerman, 1987). The enzyme is routinely isolated as a microsomal pellet, but the specific identity of the membrane association has been incompletely investigated. In spinach leaves, hydroperoxide dehydrase as well as hydroperoxide lyase are associated with whole and broken chloroplasts (Vick and Zimmerman, 1987).

\subsection{Properties}

The optimum $\mathrm{pH}$ of hydroperoxide dehydrase is between 6 and 7 (Vick and Zimmerman, 1981; Grossman et al., 1983; Vick and Zimmerman, 1987; Baertshi et al., 1988). The molecular weight of the enzyme is $250.000 \mathrm{Da}$ in cotton seedlings (Vick and Zimmerman, 1981), 220.000 in spinach leaf (Vick and Zimmerman, 1987), and 293.000 in eggplant (Grossman et al., 1983). In flaxseed, hydroperoxide lyase is described as a $55.000 \mathrm{Da}$ protein (Song and Brash, 1991) suggesting that it probably exists as a tetramer. The last authors have demonstrated the presence of a heme group in the enzyme.

\subsection{Substrate specificity}

Usually, both 9 and 13-hydroperoxides of linoleic and linolenic acids are substrates for hydroperoxide dehydrase but some plants such as cotton seedling (Vick and Zimmerman, 1981) and flaxseed (Feng and Zimmerman, 1979) have a preference for the 13isomer. Flaxseed hydroperoxide dehydrase metabolizes only the $S$ form of 13-hydroperoxilinolenic acid (Baertschi et al., 1988).

\subsection{Physiological roles of the hydroperoxide dehydrase pathway products}

The ketol products of hydroperoxide dehydrase have no known physiological role. It is possible that ketols are not formed in significant amount during in vivo metabolism in unstressed plants. Ketols may only exists as products of in vitro allene oxyde metabolism or in wounded plants where extensive cell disruption has occured (Vick, 1993).

A second product, resulting from the action of hydroperoxide dehydrase on 13-hydroperoxide of linolenic acid is 12-oxo-phytodienoic acid. This last compound is formed spontaneously from the corresponding allene oxide or by the action of an allene oxide cyclase (see figure 5).

It is the precursor of jasmonic acid which is synthetized by the successive action of 12-oxo- phytodienoic acid reductase and $\beta$-oxidation enzymes (figure 6; Vick and Zimmerman, 1984).

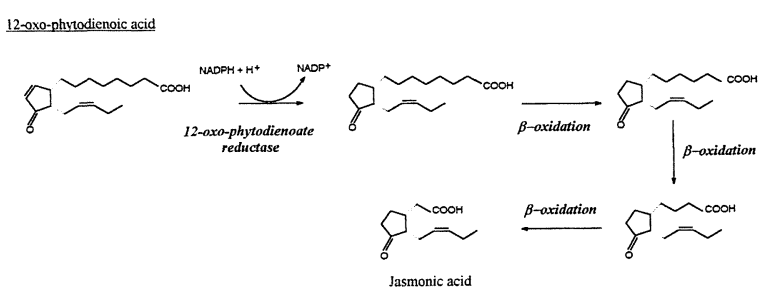

Figure 6

The jasmonic acid pathway (Vick and Zimmerman, 1984)

Allene oxide cyclase (E.C. 5.2.99.6) which catalyzes the stereospecific cyclisation of the allene oxide into 12-oxo-phytodienoic acid has been detected in several plants species but it is best-characterized from corn kernels and potato tubers. It is a soluble enzyme of about $50.000 \mathrm{Da}$ (Hamberg and Fahlstadius, 1990). 12-oxo- phytodienoate reductase (E.C. 1.3.1.42) catalyses the reduction of the $\Delta^{10}$ double bond of 12-oxo-phytodienoic acid. The enzyme has been observed in many species but its partial purification has only been described in corn kernel. The enzyme has a molecular weight of 54.000 Da and uses NADPH as co-factor (Vick and Zimmerman, 1984 and 1986). $\beta$-oxidation enzymes have only been suspected because each product retains the $Z$ configuration in the side chain (Vick, 1993). Jasmonic acid and jasmonates have often been cited to influence growth regulation. Inhibitory effects may include retardation of seedling and tissue culture growth, suppression of seed and pollen germination. Jasmonic acid frequently promotes processes associated with plant stress, such as stomatal closure, senescence, chlorophyll degradation and respiration. In many aspects, jasmonic acid shares similarities with abscisic acid (Parthier, 1991; Van den Berg and Ewing, 1991). Another role for jasmonic acid is chemical signaling in response to certain stressors (insect, mecanical, water deficit) which results in the synthesis of low molecular weight compounds (Vick, 1993).

\section{OTHER HYDROPEROXIDE METABOLIZING ACTIVITIES}

\subsection{Divinyl ether synthesis}

Potato extracts were reported to catalyze the transformation of 9-S-hydroperoxide of linoleic and linolenic acid into divinyl ethers named respectivelly colneleic and colnelenic acids (Galliard and Chan, 1980). Labeling experiments were undertaken to understand the mode of action of the enzyme (Crombie et al., 1987; Crombie and Morgan, 1987). 
The ${ }^{18} \mathrm{O}$-label from $18 \mathrm{O}_{2}$-hydroperoxide of linoleic acid was inserted into the divinyl ether moiety, and incubation of $\left(9,10,12,13-2 \mathrm{H}_{4}\right)$-9-S-hydroperoxide of linoleic acid with potato enzyme extract resulted in the retention of all four deuterium atoms. Fahlstadius and Hamberg (1990) proposed a heterolytic rearrangement for the reaction which is very similar to the one proposed for hydroperoxide dehydrase and hydroperoxide lyase (figure 7 ).

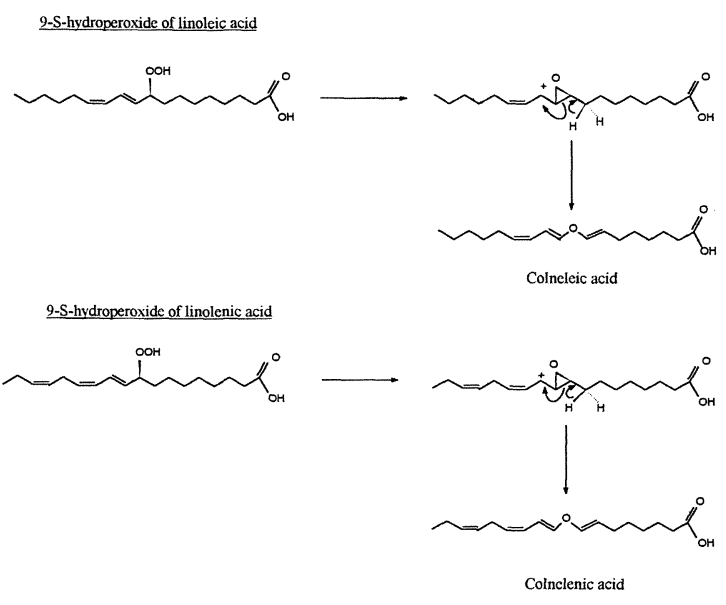

Figure 7

Divinyl ether synthesis from 9-S-hydroperoxide of linoleic and linolenic acid (Fahlstadius and Hamberg, 1990).

\subsection{Hydroperoxide isomerase}

Hydroperoxide isomerase converts fatty acids into epoxyhydroxy fatty acid. The enzyme must not be confused with the hydroperoxide isomerase described before and renamed now hydroperoxide dehydrase. Hydroperoxide isomerase has been described in cereal flours but the results are not sufficient to assign a mecanism. Hamberg (1986) reports on the transformation of 15-S-hydroperoxide of arachidonic acid into trihydroxyeicosatrienoic acid by the fungus: Saprolegnia parasitica. 9 and 13-S-hydroperoxides of linoleic acid are also substrates for the enzyme (Hamberg, 1989). The enzyme is soluble and cannot be distinguished from the lipoxygenase catalysis. Both activities seem to be situated on the same protein or on the same protein complex (Herman and Hamberg, 1987).

\subsection{Hydroperoxide dependent peroxygenase and epoxygenase (Gardner, 1991)}

The reaction catalyzed by those two enzymes is characterized by the reduction of fatty acid hydroperoxides in hydroxy fatty acids and by the concomitant oxidation of unsaturated fatty acids in epoxides. The oxygen of the epoxy group originates from the hydroperoxide group. The addition of oxygen is sterospecific and retains the $Z$ configuration of the initial fatty acid. Microsomal hydroperoxide dependent peroxygenase from soybean (Blee and Schuber, 1990), or hydroperoxide dependant epoxygenase from Vicia faba (Hamberg and Hamberg, 1990), catalyzed the epoxydation of unsaturated fatty acids in the presence of 13-S-hydroperoxide of linoleic acid. The enzymes form 9,10 epoxide from oleic and 12,13 epoxide from linoleic acid. The soybean enzyme can also synthetize a 9, 10, 12, 13-di-epoxide. The two enzymes have some common features in their catalysis mecanisms but they afford differences in the stereospecificity of epoxidation. That is why separated nomenclatures are suggested. In fact, soybean and Vicia faba extracts furnish $9-\mathrm{R}, 10-\mathrm{S}$ epoxides but the 12 , 13-epoxides have opposite stereochemistry (12-S, 13-R for Vicia faba and 12-R, 13-S for soybean).

\section{BIBLIOGRAPHY}

Andrianarison, R. H., Beneytout, J. L. and Tixier, M. (1989). -«An enzymatic conversion of lipoxygenase products by a hydroperoxide lyase in blue-green algae (Oscillatoria sp.)".Plant Physiol. 91, 1280-1287.

Baertschi, S. W., Ingram, C. D., Harris, T. M. and Brash, A.R. (1988). - «Absolute configuration of cis-12-oxophytodienoic acid of flaxseed: implications for the mecanism of biosynthesis from the 13(S)-hydroperoxide of linolenic acid".- Biochemistry 27, 18-24.

Berger, R. G., Kler, A. and Drawert, F. (1986). -«The C-6 aldehyde forming system in Agropyron repens".- Biochim. Biophys. Acta. 883, 523-530.

Brash, A. R., Baertschi, S. W., Ingram, C. D. and Harris, T. M. (1987). - «On non-cyclogenase prostaglandin synthesis in the sea whip coral, Plexaura homomalla: an $8(\mathrm{R})$ lipoxygenase pathway leads to formation of an a-ketol and a racemic prostanoid".- J. Biol. Chem. 262, 15829-15839.

Blée E. and Scuber F. (1990). - Efficient epoxidation of unsaturated fatty acids by a hydroperoxide-dependant oxygenase".- J. Biol. Chem. 265, 12887-12894.

Corey, E. J., d'Alarcao, M., Matsuda, S. P. T. and Lansbury, P. T. (1987). - «Intermediacy of 8(R)-HPETE in the conversion of arachidonic acid to pre-clavulone $\mathrm{A}$ by Clavularia viridis. Implications for the biosynthesis of marine prostanoids".- $J$. Am. Chem. Soc. 109, 289-290.

Crombie, L., Morgan, D. O. and Smith, E. H. (1987). - «The enzymic formation of colneleic acid, a divinyl ether fatty acid: experiments with (9-S-18O2) hydroperoxioctadeca-10-E, 12 Z-dienoic acid».- J. Chem. Soc. Chem. Comm. 502-503.

Crombie, L., Morgan, D. O. (1987). - «Experiments with (9, 10, 12 , $13-{ }^{2} \mathrm{H}_{4}$ ) linoleic acid on the formation of 9 -(nona-(1'E), (3'Z)dienyloxy)non-(8E)-enoic (colneleic) acid and (13R)-hydroxy12-OXO-octadec-(9Z)-enoic acid by plant enzymes".- J. Chem. Soc. Chem. Commun. 503-504.

Fahlstadius, P. and Hamberg, M. (1990). - «Stereospecific removal of the pro- $\mathrm{R}$ hydrogen at $\mathrm{C}-8$ of (9S) hydroperoxyoctadecadienoic acid in the biosynthesis of colneleic acid".- J. Chem. Soc. 2027-2030.

Feng, P. and Zimmerman, D. C. (1979). - «Substrate specificity of flax hydroperoxide isomerase".- Lipids 14, 710-713.

Galliard, T. and Philips, D. R. (1976). - «The enzymic cleavage of linoleic acid to C-9 carbonyl fragments in extracts of 
cucumber (Cucumis sativus) fruit and the possible role of lipoxygenase».- Biochim. Biophys. Acta. 431, 278-287.

Galliard, T.; Mattew, J. A., Wright, A. J. and Fishwick, M. J. (1977) - «The enzymic breakdown of lipids to volatile and nonvolatile carbonyl fragments in disrupted tomato fruits".- J. Sci. Food Agric. 28, 863-868.

Galliard, T. and Chan, H. W. S. (1980). - «Lipoxygenases» in "The biochemistry of plants: a comprehensive treatise» p. 131. Vol. 4. Lipids: structure and function. Stumpf, P. K. and Conn, E.E. (Ed.)-Academic press, New York.

Gardner, H. W. (1991). - «Recent investigations into the lipoxygenase pathway of plants».- Biochim. Biophys. Acta. 1084, 221-239.

Gardner H. W. (1970). - «Sequential enzymes of linoleic oxidation in corn germ: lipoxygenase and linoleate hydroperoxide isomerase».- J. Lipid Res. 11, 311-321.

Gardner, H. W., Plattner, R. D. (1984). -«Linoleate hydroperoxides are cleaved heterolytically into aldehydes by a Lewis acid in aprotic solvent". - Lipids 19 (4), 294-299.

Götz-Schmidt, E. M., Wenzel, M. and Schreier, P. (1986). -«C-6 volatiles in homogenates from green leaves: localization of hydroperoxide lyase activity».- Lebensm. Wiss. Technol. 19, 152-155.

Grossman, S., Bergman, M. and Sofer, Y. (1983). -«Purification and partial characterization of eggplant linoleate hydroperoxide isomerase».- Biochim. Biophys. Acta. 752, 65-72.

Hamberg, M. (1986). - «Isolation and structure of lipoxygenase from Saprolegnia parasitica».- Biochim. Biophys. Acta. 876, 688-692.

Hamberg, M. (1987). - «Mecanism of corn hydroperoxide isomerase: detection of 12.13-S-oxido-9-Z-octadecadienoic acid».- Biochim. Biophys. Acta 920, 76-84.

Hamberg, M. (1989). - «Fatty acid hydroperoxide isomerase in Saprolegnia parasitica: structural studies of epoxy alcohols formed from isomeric hydroperoxyoctadecadienoates".Lipids 24, 249-255.

Hamberg, M. and Hamberg G. (1990). - «ydroperoxide dependent epoxidation of unsaturated fatty-acids in broad bean (Vicia faba L.)".- Arch. Biochem. Biophys. 283, 409416.

Hamberg, M., and Fahlstadius, P. (1990). - «Allene oxide cyclase: a new enzyme in plant metabolism".- Arch. Biochem. Biophys. 276, 518-526.

Hatanaka, A., Kajiwara, T., Sekiya, J. and Inoue, S. (1982). - «Solubilization and properties of the enzyme-cleaving 13-1hydroperoxilinolenic acid in tea leaves".- Phytochemistry 21, 13-17.

Hatanaka, A., Kajiwara, T., Sekiya, J. and Toyota H. (1986). - Oxygen incorporation in cleavage of ${ }^{18} \mathrm{O}$ labeled 13 hydroperoxylinoleyl alcohol into 12-hydroperoxy (3Z)dodecenalin tea chloroplasts".- Z. Naturforsch. 41c, 359362.

Hatanaka, A., Kajiwara, T., Matsui, K. and Toyota H. (1992). - «Substrate specificity of tea leaf hydroperoxide lyase».- $Z$. Naturforsch. 47c, 677-679.

Hatanaka, A. (1993). - «The biogeneration of green odour by green leaves".- Phytochemistry 34 (5), 1201-1218.

Herman, R. P. and Hamberg, M. (1987). - «Properties of the soluble arachidonic acid 15-lipoxygenase and 15hydroperoxide isomerase from the oomycete Saprolegnia parasitica".- Prostaglandins 34, 129-139.

Kim, I. S. and Grosch, W. (1981). - «Partial purification and properties of a hydroperoxide lyase from fruits of pear».- J. Agric. Food Chem. 29, 1220-1225.

Lyr, H., and Banasiak, L. (1983). - «Alkenals, volatile defense substances in plants, their properties and activities».- Acta Phytopathol. Acad. Sci. Hung. 18, 3-12.

Martini, D. and lacazio, G. (1995). - “Les lipoxygénases et les voies métaboliques associées".- Oléagineux. Corps gras Lipides 2 (5), 374-385.
Matoba, T., Hidaka, H., Kitamura, K., Kaizuma, N. and Kito, M. (1985). - «Contribution of hydroperoxide lyase activity to nhexanal formation in soybean».- J. Agric. Food Chem. 33, 856-858.

Matsui, K., Shibata, Y., Kajiwara, T. and Hatanaka, A. (1989). - «Separation of 13- and 9- hydroperoxide lyase activities in cotyledons of cucumber seedlings".- Z Z Naturforsch. 44c, 883-885.

Matsui, K., Toyota, H., Kajiwara, T., Kakuno, T. and Hatanaka, A. (1991). - «Fatty acid hydroperoxide cleaving enzyme, hydroperoxide lyase from tea leaves".- Phytochemistry $\mathbf{3 0}$, 2109-2113.

Matsui, K., Kajiwara, T. and Hatanaka, A., (1992). -«Inactivation of tea leaf hydroperoxide lyase by fatty acid hydroperoxide".J. Agric. Food Chem. 40, 175-178.

Matthew, J. A. and Galliard, T. (1978). - «Enzymic formation of carbonyls from linoleic acid in leaves of Phaseolus vulgaris".-Phytochemistry 17, 1043-1044.

Olias, J. M., Rios, J. J., Valle, M., Zamora, R., Sanz, L. C. and Axelrod, B. A. (1990). - «Fatty acid hydroperoxide lyase in germinating soybean seedlings».- J. Agric. Food Chem. 38, 624-630.

Parthier, B. (1991). - «Jasmonates, new regulators of plant growth and development: many facts and few hypotheses on their action".- Bot. Acta. 104, 446-456.

Schildknecht, H. and Rauch, G. (1961). -«Defensive substances of plants. II. Chemical nature of the volatile phytocides of leafy plants, particularly of Robinia pseudoacacia».- Z. Naturforsch. 16b, 422-429.

Schreier, P. and Lorenz, G. (1982). - «Separation, partial purification and characterization of a fatty acid hydroperoxide cleaving enzyme from apple and tomato fruits".- $Z$. Naturforsch. 37c, 165-173.

Sekiya, J., Kajiwara, T., and Hatanaka, A. (1979). - «Volatile C-6 aldehyde formation via hydroperoxides from C-18 unsaturated fatty acids in etiolated alflfa and cucumber seedlings".- Agric. Biol. Chem. 43, 969-980.

Sekiya, J., Kajiwara, T., Munechika, K. and Hatanaka, A. (1983). - «Distribution of lipoxygenase and hydroperoxide lyase in the leaves of various plant species».- Phytochemistry 22 (9), 1867-1869.

Sekiya, J., Tanigawa, S., Kajiwara, T. and Hatanaka, A. (1984). - «Fatty acid hydroperoxide lyase in tobacco cells cultured in vitro".- Phytochemistry 23, 2439-2443.

Shibata, Y., Matsui, K., Kajiwara, T. and Hatanaka, A. (1995a). - «Purification and properties of fatty acid hydroperoxide lyase from green bell pepper fruits".- Plant Cell Physiol. 36 (1), 147-156.

Shibata, Y., Matsui, K., Kajiwara, T. and Hatanaka, A. (1995b). - «Fatty acid hydroperoxide lyase is a heme protein».Biochem. Biophys. Res. Comm. 207 (1), 438-443.

Song, W. C. and Brash, A. R. (1991). - «Purification of an allene oxide synthase and identification of the enzyme as a cytochrome P-450". - Science 253, 781-783.

Tressl, R., and Drawert, F. (1973). - «Biogenesis of banana volatiles".- J. Agric. Food Chem. 21 (4), 560-565.

Van den Berg, J.H. and Ewing, E.E. (1991). - «Jasmonates and their role in plant growth and development, with special references to the control of potato tuberization: a review».Am. Potato 68, 781-790.

Vick, B.A. and Zimmerman, D.C. (1986). - "Characterization of 12-OXO-phytodienoic acid reductase in corn; the jasmonic acid pathway».- Plant Physiol. 80, 802-805.

Vick, B.A. and Zimmerman, D.C. (1987). - «Pathways of fatty acid hydroperoxide metabolism in spinach leaf chloroplasts".Plant Physiol. 85, 1073-1078.

Vick, B.A. and Zimmerman, D.C. (1989). - «Metabolism of fatty acid hydroperoxides by Chlorella pyrenoidosa".- Plant Physiol. 90, 125-132.

Vick, B.A., Zimmerman, D.C. (1976). - «Lipoxygenase and hydroperoxide lyase in germinating watermelon seedlings". Plant Physiol. 57, 780-788. 
Vick, B.A. and Zimmerman, D.C. (1979). - «Distribution of a fatty acid cyclase enzyme system in plants».- Plant Physiol. 64, 203-205.

Vick, B.A. and Zimmerman, D.C. (1981). - «Lipoxigenase, hydroperoxide isomerase, and hydroperoxide cyclase in young cotton seedlings".- Plant Physiol. 67, 92-97.

Vick, B.A. and Zimmerman, D.C. (1983). - «The biosynthesis of jasmonic acid: a physiological role for plant lipoxygenase".Biochem. Biophys. Res. Commun. 111, 470-477.

Vick, B.A. (1993). - "Oxygenated fatty acid of the lipoxygenase pathway".- in: "Lipid metabolism in plants». p. 168. Moore, T.S. (Ed.). CRC press, Boca Raton, U.S.A.

Vick, B.A. and Zimmerman, D.C. (1984). - «Biosynthesis of jasmonic acid by several plant species".- Plant Physiol. 75 , 458-461.

Wardale, D.A., Lambert, E.A. and Galliard, T. (1978). - «Fatty acid hydroperoxide cleavage in cucumber".- Phytochemistry 17 , 205-212.

Wurzenberger, M. and Grosch, W. (1984a). - «Stereochemistry of the cleavage of the 10-hydroperoxide isomer of linoleic acid to 1-octen-3-ol by a hydroperoxide lyase from mushrooms (Psalliota bispora)».- Biochim. Biophys. Acta. 795, 163-165.

Wurzenberger, M. and Grosch, W. (1984b). - «The formation of 1 octen-3-ol from the 10-hydroperoxide isomer of linoleic acid by a hydroperoxide lyase in mushrooms (Psalliota bispora)".- B.B.A. 794, 25-30.

Yabuuchi, S. and Amaha, M. (1976). - «Partial purification and characterization of the linoleate hydroperoxide isomerase from grains of Hordeum distichum».- Phytochemistry 15 , 387-390.

Zeringue, H.J. and Mc Cormick, S.P. (1989). -«Relationships between cotton leaf-derived volatiles and growth of Aspergillus flavus".- J. Am. Oil Chem. Soc. 66, 581-584.

Zimmerman, D.C. (1966). - «A new product of linoleic acid oxidation by flaxseed enzyme».- Biochem. Biophys. Res. Comm. 23, 398-402.

Zimmerman, D.C. and Feng, P. (1978). - «Characterization of a prostaglandin-like metabolite of linolenic acid produced by a flaxseed extract».- Lipids 13, 313-316.

Zimmerman, D.C. and Vick, B.A. (1970). -«Hydroperoxide isomerase».- Plant Physiol. 46, 445-453.

Zimmerman, D.C. and Coudron, C. (1979). - «Identification of traumatin, a wound hormone, as 12-oxo-trans-10dodecenoic acid».- Plant Physiol. 63, 536-541.

Recibido: Septiembre 1996 Aceptado: Febrero 1997 